\title{
ЭЛЕМЕНТЫ ОПТИМИЗАЦИИ ТЕХНОЛОГИИ СОХРАНЕНИЯ СМОРОДИНЫ ЧЕРНОЙ IN VITRО
}

\author{
I.V. Knyazeva, V.N. Sorokopudov, O.A. Sorokopudova
}

\section{THE ELEMENTS OF OPTIMIZATION OF THE TECHNOLOGY FOR THE CONSERVATION OF BLACK CURRANT IN VITRO}

\begin{abstract}
Князева Инна Валерьевна - канд. биол. наук, ст. науч. сотр. лаб. исследований технологических свойств сельскохозяйственных материалов Федерального научного агроинженерного центра ВИМ, Федеральный научный селекционно-технологический центр садоводства и питомниководства, г. Москва. E-mail: knyazewa.inna@yandex.ru
\end{abstract}

Сорокопудов Владимир Николаевич - д-р с.-х. наук, проф. каф. декоративного садоводства и газоноведения Российского государственного аграрного университета - МСХА им. К.А. Тимирязева, Федеральный научный селекционно-технологический центр садоводства и питомниководства, г. Москва. E-mail: sorokopud2301@mail.ru

Сорокопудова Ольга Анатольевна - д-р биол. наук, проф. каф. ботаники, селекции и семеноводства садовых растений Российского государственного аграрного университета - МСХА им. К.А. Тимирязева, Федеральный научный селекционнотехнологический центр садоводства и питомниководства, г. Москва.

E-mail: o.sorokopudova@rgau-msha.ru

В результате исследований установлено, что коллекционные образцы смородины черной в условиях in vitro можно поддерживать в жизнеспособном состоянии на специально подобранных по составу питательных средах. Проведена отработка элементов технологии сохранения растений с помощью приемов культивирования клеток, тканей и органов in vitro, что является наиболее безопасной альтернативой для дублетных коллекций большого количества культур. Цель работы - разработка элементов технологии длительного сохранения ценных генотипов смородины черной путем использования осмотически активных веществ в сочетании с различными температурными режимами депонирования. Onределены оптимальные условия культивирования для экплантов смородины черной сорта
Knyazeva Inna Valeryevna - Cand. Biol. Sci., Senior Staff Scientist, Lab. of the Researches of Technological Properties of Agricultural Materials, Federal Scientific Agroengineering center VIM, Federal Scientific Selection and Technology Center for Horticulture and Nursery, Moscow. E-mail: knyazewa .inna@yandex.ru

Sorokopudov Vladimir Nikolaevich - Dr. Agr. Sci., Prof., Prof. Chair of Decorative Gardening and Lawn Science, Russian State Agrarian University - MAA named after K.A. Timiryazev, Federal Scientific Selection and Technology Center for Horticulture and Nursery, Moscow. E-mail: sorokopud2301@mail.ru

Sorokopudova Olga Anatolyevna - Dr. Biol. Sci., Prof., Chair of Botany, Selection and Seed Farming of Garden Plants, Russian State Agrarian University MAA named after K.A. Timiryazev, Federal Scientific Selection and Technology Center for Horticulture and Nursery, Moscow.

E-mail: o.sorokopudova@rgau-msha.ru

Брянский Агат на среде с добавлением маннита в концентрациях 0,45 и 0,75 \% при температуре 22-24 ㄷ. Совместное использование маннита в указанных концентрациях и температуры позволило сохранить жизнеспособность растений на уровне 40 \%. Сравнительный анализ влияния различных осмотически активных веществ на регенерацию микрочеренков показал целесообразность использования маннита в условиях нормальной скорости роста, так как его внесение в питательную среду в разных концентрациях повышало жизнеспособность эксплантов по сравнению с дульцитом в 5-8 раз и контролем - в 2-2,5 раза. При депонировании в условиях низких положительных температур 4-6 $\mathrm{C}$ оптимальным источником органического питания оказалась сахароза. Жизнеспособность кон- 
трольных образцов была выше (55 \%), чем опытных (25\%). Таким образом, на модельном сорте Брянский Агат смородины черной выявлена возможность сохранения эксплантов на протяжении 12 месяцев беспересадочного культивирования путем модифрикации питательной среды на основе осмотически активных веществ и температурных режимов. Реализация морфогенетического потенциала культивируемых эксплантов обусловлена генотипом, составом питательной среды и условиями культивирования. В результате определения оптимальных условий культивирования для эксплантов смородины черной сорта Брянский Агат были разработаны элементы технологии сохранения ценных генотипов смородины черной в условиях in vitro.

Ключевые слова: смородина черная, маннит, дульцит, депонирование, жизнеспособность, in vitro.

As a result of the studies it was found out that the collection samples of black currant in vitro conditions can be maintained in a viable state on specially selected nutrient media. The elements of plant conservation technology were tested using in vitro the cultivation of cells, tissues and organs, which is the safest alternative for doublet collections of a large number of cultures. The aim of the study was to develop the elements of the technology for long-term preservation of valuable genotypes of black currant by using osmotically active substances in combination with various temperature conditions of deposition. Optimal cultivation conditions for the explants of black currant variety 'Bryansky Agat' on the medium supplemented with mannitol at the concentrations of $0.45 \%$ and $0.75 \%$ and the temperature plus 22-24 degrees Centigrade were determined. The joint use of mannitol in indicated concentrations and the temperature allowed maintaining the viability of plants at the level of 40-50\%. Comparative analysis of the influence of various osmotically active substances on micrograins' regeneration showed the feasibility of using mannitol under the conditions of normal growth rate, since its introduction into the nutrient medium at different concentrations increased the viability of explants compared with dulcite by 5-8 times and control by 2-2.5 times. When deposited under the conditions of low positive temperatures plus 4-6 degrees Centigrade, sucrose was the optimal source of organic nutrition. The viability of control samples was higher (55\%) than that of experimental ones - $25 \%$. Thus, the possibility of preserving the explants for 12 months of direct cultivation by modifying the nutrient medium based on osmotically active substances and temperature conditions was revealed on the model variety of black currant 'Bryansky Agat'. The realization of morphogenetic potential of cultivated explants is determined by the genotypes, the composition of the nutrient medium, and cultivation conditions. Having identified the optimal source of mineral nutrition, its concentration and combined with the temperature factor, the elements of the technology for the conservation of valuable genotypes of black currant in vitro were developed.

Keywords: black currant, mannitol, dulcite, depositing, vitality, in vitro.

Введение. Совершенствование биотехнологических методов и приемов позволит сохранить длительное время растительные объекты и создать генетические коллекции в контролируемых условиях среды. Сохранение гермоплазмы растений имеют важное значение для международного сообщества генетических ресурсов, а валидация протоколов среди действующих генетических банков позволит интегрировать новые технологии в программы генетических ресурсов растений. Использование современных биотехнологических приемов, в том числе клонального микроразмножения, позволит решить проблему размножения и сохранения генетически ценного материала, свободного от патогенов и вредителей $[1,2]$.

Методы хранения in vitro растительного материала включают среднесрочное сохранение в условиях медленнорастущей культуры и криоконсервирование. Для криоконсервации многих ягодных культур, включая культурные сорта и дикие разновидности смородины черной, используют контролируемое программное замораживание, методы витрификации, инкапсуляции-дегидратации и витрификациидегидратации $[3,4]$. Результаты проведенных исследований в Институте биологии и биотехнологии растений Национального центра биотехнологии Республики Казахстан показывают, что генофонд гермоплазмы смородины черной может быть надежно сохранен в жидком азоте как долгосрочная резервная коллекция in vitro в дополнение к активной полевой коллекции, поддерживаемой в помологических и ботанических садах [5]. 
Эфффективность размножения и сохранения большинства культур методом in vitro во многом зависит от состава питательной среды, регуляторов роста, генотипа и фризических фракторов (температуры, освещенности и влажности) [68]. Растения $R$. nigrum, культивируемые in vitro, имеют характерные особенности в сравнении с другими ягодными культурами (например, Rubus idaeus L.). Таким отличием является формирование коротких побегов на этапе собственно размножения при культивировании растений на питательной среде с цитокининами [9]. Модифицированную питательную среду МС (Мурасиге и Скуга), дополненную 6-БАП (6бензиламинопурином) и ИМК (индолилмасляной кислотой) в концентрациях 0,8 и 0,1 мг/л, целесообразно применять для беспересадочного хранения эксплантов смородины черной в течение 3-4 месяцев в межсезонный период $[10,11]$. Особенностью работ in vitro является разработка протоколов клонального микроразмножения применительно для каждого сорта и генотипа с учетом биологических особенностей [12-14]. Клональное микроразмножение смородины черной является перспективным способом репродукции этой культуры, обеспечивающим высокий коэффрициент размножения и возможность сохранения эксплантов в генетических коллекциях in vitro [15].

Смородина черная Ribes nigrum L. - одна из самых распространенных ягодных культур в России, Украине, Казахстане, Белоруси, Польше, Нидерландах, Франции и Новой Зеландии [16-19] благодаря наличию в ней высоких концентраций широкого спектра биологически активных веществ, антиоксидантов, сахаров, витаминов и минеральных компонентов [20].

Цель исследований. Разработка элементов технологии длительного сохранения ценных генотипов смородины черной путем использования осмотически активных веществ в сочетании с различными температурными режимами депонирования.

Материалы и методы. Исследования по сохранению эксплантов смородины черной (Ribes nigrum L.) сорта Брянский Агат в культуре in vitro и определению жизнеспособности микропобегов проводили в лаборатории биотехнологии на базе ФГБНУ «Всероссийский селекционнотехнологический институт садоводства и питомниководства» (ФГБНУ ВСТИСП, Г. Москва) в 2018-2019 гг. в соответствии с методическими рекомендациями [21]. Для регенерации эксплантов использовали модифицированную питательную среду Мурасиге и Скуга (МС): 0,7 мг/л 6-бензиламинопурина (БАП), 0,1 мг/л индолил3-масленной кислоты (ИМК), витаминный комплекс (мг/л): тиамин (B1), пиридоксин (B6), никотиновая кислота (РP) - по 0,5 и аскорбиновая кислота (C) - 1,0 мг/л и 8 г/л агар-агара (Panreac, Spain), pH 5,7. Экспланты высаживали на среду с добавлением соединений маннита и дульцита в концентрации 0,45 \% (1-й вариант); 0,75 \% (2-й вариант) и 1,05\% (3-й вариант). Контроль - среда с добавлением сахарозы $3,0 \%$. Жизнеспособность образцов оценивали визуально (количество живых и погибших растений, \%) один раз в месяц.

Работы по изолированию эксплантов проводили в асептических условиях - ламинарных боксах Lamsystems (Россия). Питательные среды автоклавировали при давлении 1.0 атм (20 мин) в стерилизаторе ВК-75-01 (Россия). Культивирование осуществляли в климатической камере КС-200 (Россия) в стандартных ус-

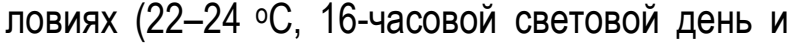
освещенность 3000-5000 люкс); среднесрочное депонирование эксплантов - в холодильной камepe Liebherr (Германия) с регулируемой температурой от 3 до $6{ }^{\circ} \mathrm{C}$, интенсивностью освещения 70-80 мкМ м² $\mathrm{c}^{-1}$ и фотопериодом 8/16 ч. Микропобеги предварительно адаптировали к пониженным температурам, в течение двух недель содержали в климатической камере, затем экспланты переносили на среднесрочное хранение в холодильную камеру. В опытах по сохранению эксплантов учитывали основные факторы, такие как температура, состав питательной среды и жизнеспособность эксплантов.

Результаты и их обсуждение. Внесение в питательную среду маннита в разных концентрациях увеличивало длительность хранения и срок жизнеспособности микрорастений смородины черной. Спустя 12 месяцев беспересадочного культивирования при температуре 22-24 ㄷ жизнеспособность эксплантов составила 25-40 \% в зависимости от концентрации маннита, тогда как в контроле - $15 \%$. Оптимальной оказалась концентрация маннита 0,45 \%, при использовании которой экспланты дольше сохраняли жизнеспособность. В то же время экспланты на питательной среде с добавлением дульцита погибли в вариантах 2 и 3 спустя 6-9 месяцев культивирования (рис. 1). 


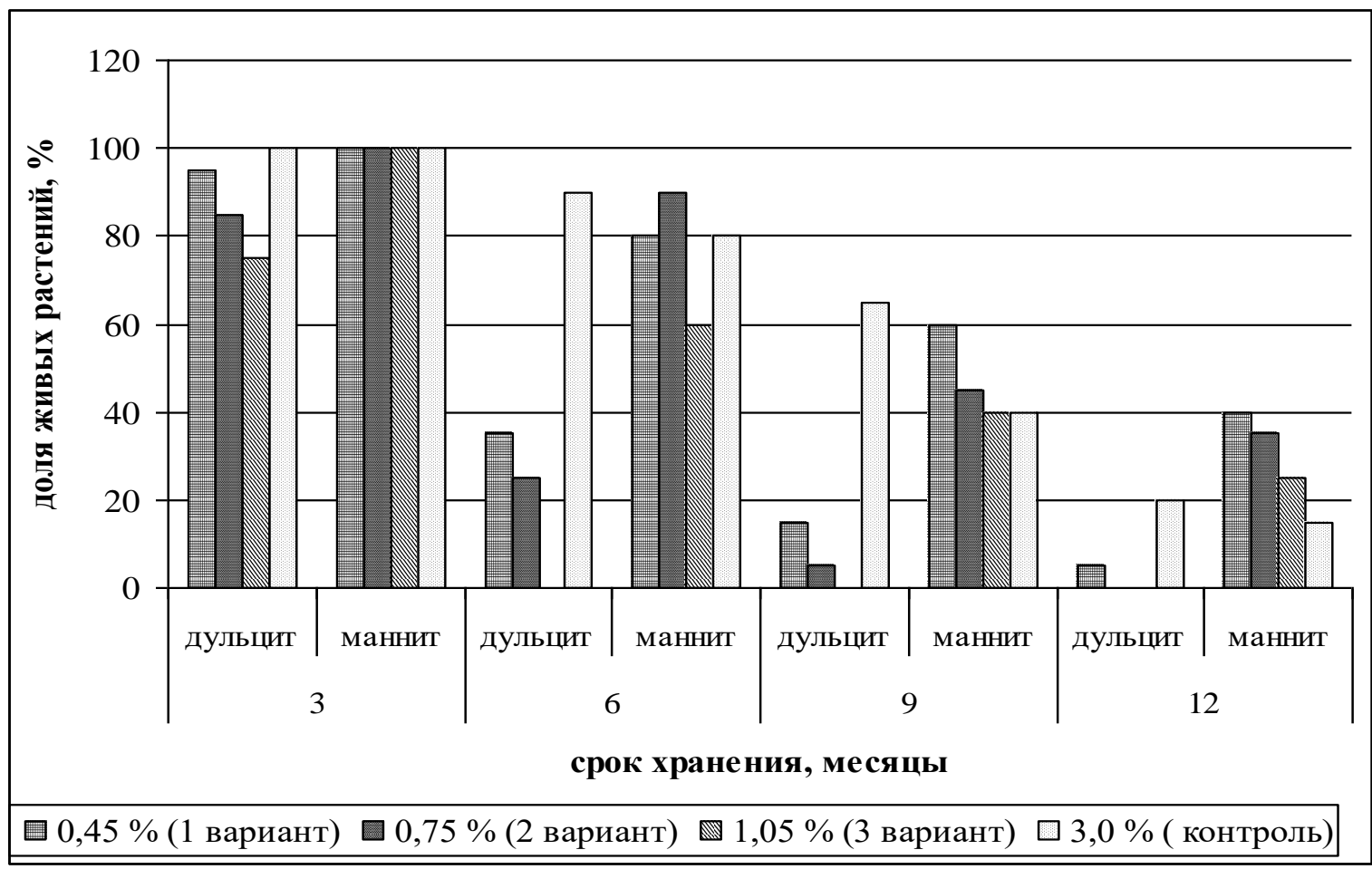

Puс. 1. Влияние сахаров и шестиатомных спиртов на сохранение эксплантов смородины черной сорта Брянский Агат при температуре 22-24 ㄷ

В процессе исследований показано, что использование осмотических соединений различной концентрации при температуре 22-24 ${ }^{\circ} \mathrm{C}$ значительно увеличивало как период беспересадочного культивирования, так и жизнеспособность эксплантов смородины черной (рис. 2). Наблюдения показали, что внесение в питательную среду маннита в разных концентрациях

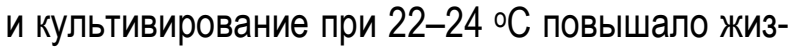
неспособность микрорастений по сравнению с дульцитом в 5-8 раз и контролем - в 2-2,5 раза.

В условиях пониженных положительных температур 4-6 ㄷ сохранность микрорастений сорта Брянский Агат через 12 месяцев варьировала в пределах 25-40 \% (маннит) и 5-10 \% (дульцит), в то время как в контроле она была выше и составляла 50-55 \% (рис. 3). Как показали наши исследования, добавление в питательную среду маннита в концентрации 1,05 \% сохраняло жизнеспособность микрорастений на уровне $40 \%$. Необходимо отметить, что экспланты, помещенные на среду с дульцитом в условиях пониженных температур, хранились дольше в вариантах 1 и 2 на протяжении 12 месяцев культивирования по сравнению с 3-м вариантом, в котором они погибли уже через 9 месяцев культивирования. Однако в целом более высокий процент живых эксплантов смородины черной при температуре 4-6 ${ }^{\circ} \mathrm{C}$ отмечали в контрольном варианте на среде с добавлением сахарозы.

Следовательно, при изучении влияния температурного режима и минерального состава питательной среды на хранение эксплантов смородины черной сорта Брянский Агат определены оптимальные условия культивирования на среде с добавлением маннита в концентрациях 0,45 и 0,75\% при температуре 22-24 C. Совместное использование маннита в указанных концентрациях и температуры позволило увеличить сроки беспересадочного хранения микрорастений до 12 месяцев и сохранить жизнеспособность растений на уровне 40,0 \%. При депонировании в условиях низких положительных температур (4-6 ㄷ) оптимальным источником органического питания оказалась сахароза. Жизнеспособность контрольных образцов была выше (50-55 \%), чем опытных (25-40\%). 


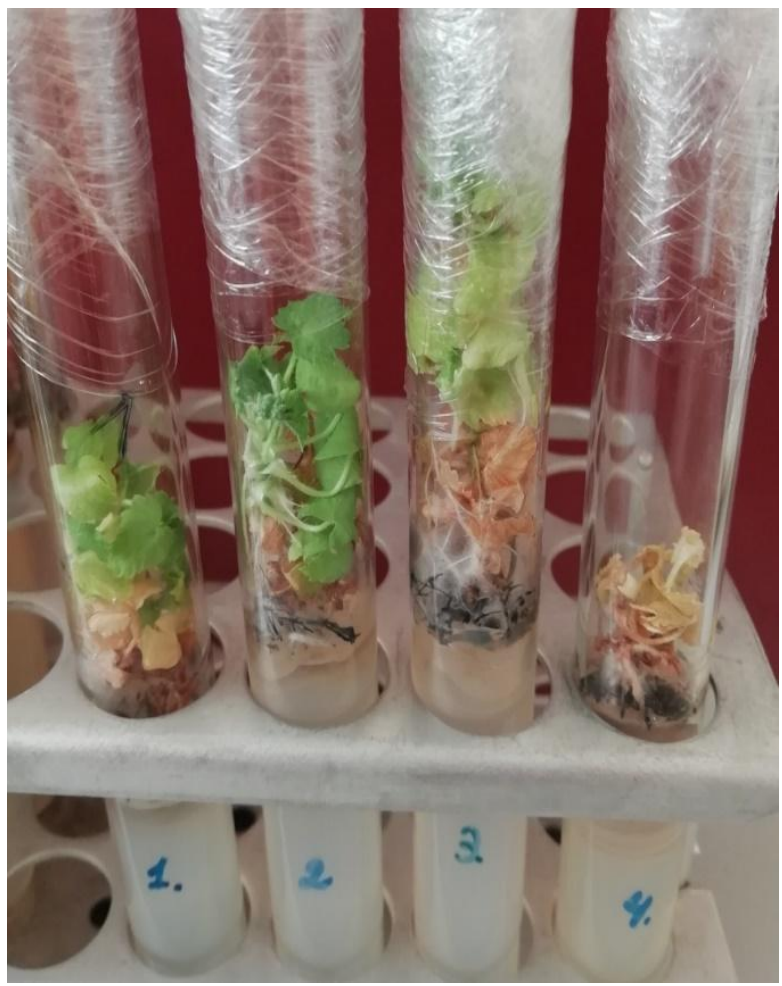

Puс. 2. Влияние условий культивирования на жизнеспособность микрочеренков смородины черной сорта Брянский Агат (через 11 месяцев депонирования при температуре 22-24 ㄷ) на питательных средах с различными концентрациями маннита: 1-й вариант (0,45 \%), 2-й вариант (0,75 \%), 3-й вариант (1,05\%), K - контроль (сахароза 3,0 \%)

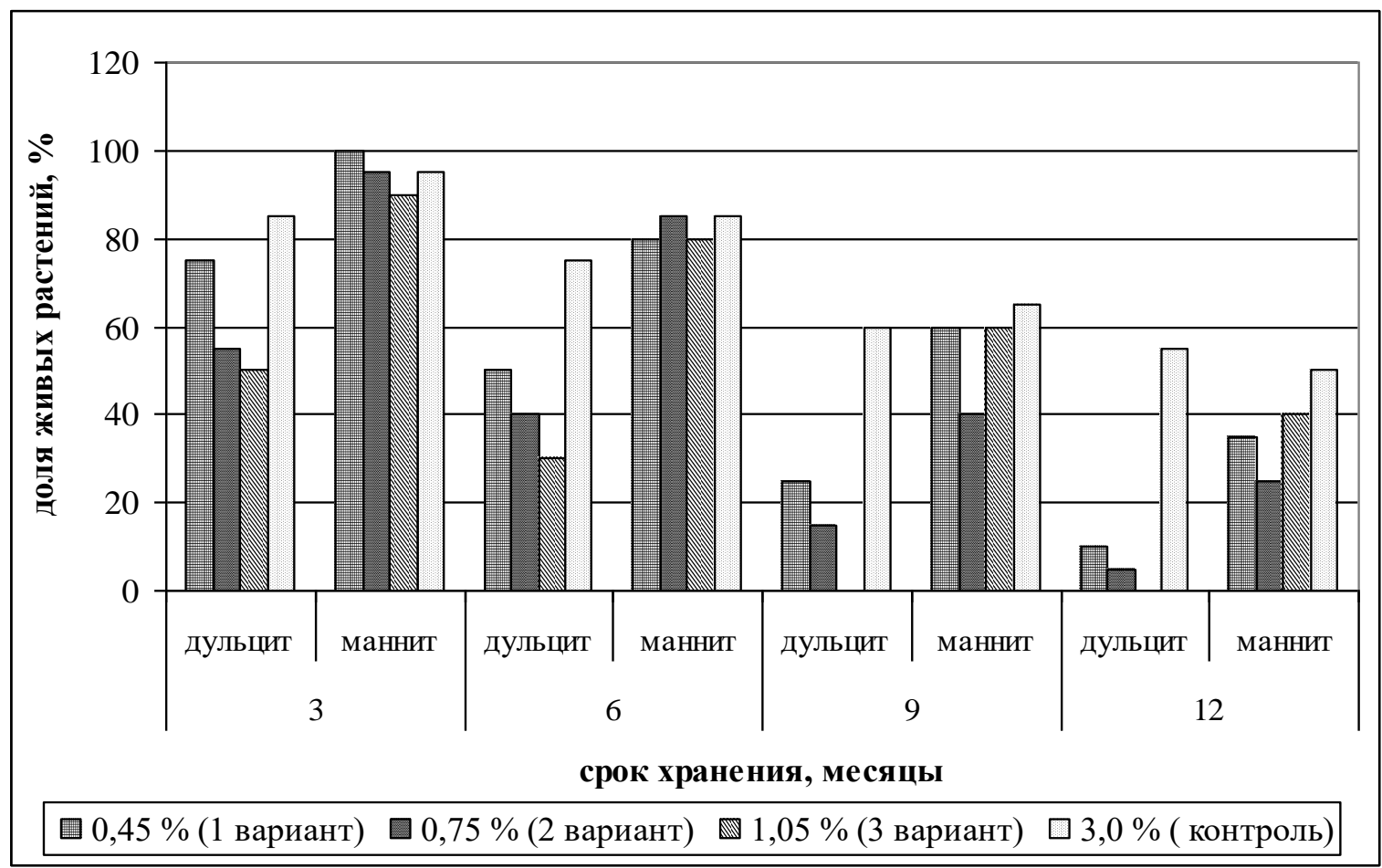

Pис. 3. Влияние сахаров и шестиатомных спиртов на сохранение эксплантов смородины черной сорта Брянский Агат при температуре 4-6 C 
Выводы. Для замедления ростовых процессов и сохранения ценных генотипов смородины черной сорта Брянский Агат в контролируемых условиях in vitro при температуре 22-24 ${ }^{\circ} \mathrm{C}$ в состав питательной среды рекомендуется добавлять маннит в пониженной концентрации $(0,45 \%)$. Жизнеспособность микрорастений сохранялась на уровне $50 \%$ через 12 месяцев культивирования. При депонировании в условиях низких положительных температур (4-6 ㅇ) оптимальным источником минерального питания оказалась сахароза. Выход жизнеспособных эксплантов на питательной среде с сахарозой составил до 55 \% у сорта Брянский Агат.

\section{Литература}

1. Hai Ren, Haining Qin, Zhiyun Ouyang, Xiangying Wen, Lina Zhao Progress of implementation on the Global Strategy for Plant Conservation in (2011-2020) China // Biological Conservation. 2019. V. 230. P. 169-178. DOI: 10.1016/.biocon.2018.12.030.

2. Höfer M., Flachowsky H., Hanke M-V. German Fruit Genebank - looking back 10 years after launching a national network for sustainable preservation of fruit genetic resources // Journal für Kulturpflanzen. 2019. V. 71 (2/3). P. 41-51. DOI: 10.5073/JfK.2019.02-03.01.

3. Reed B.M. Cryopreservation of Temperate Berry Crops // Plant Cryopreservation: A Practical Guide. New York: Springer Science Business Media LLC. 2008. P. 333-364.

4. Engelmann F., Gonzalez Arnao M.T., Wu Y., Escobar R.H. Development of Encapsulation Dehydration // Plant Cryopreservation: A Practical Guide. New York: Springer Science Business Media LLC. 2008. P. 59-76.

5. Ковальчук И.Ю., Турдиев Т.Т. Оптимизация методов криоконсервации гермоплазмы черной смородины (Ribes nigrum L.) // Биотехнология. Теория и практика. 2010. № 2. C. 54-61.

6. Manole C.G., Balan V., Mencinicopschi I.C., Golea D., Rodino S., Butu A. The influence of growth regulators concentrations on in vitro micropropagation of Ribes rubrum Species /I Scientific Bulletin, Series F, Biotechnologies. Vol. XVI. 2012. P. 26-29.
7. Volk G.M., Bramel P.A. Strategy to conserve worldwide apple genetic resources: survey results. // Acta Hortic. 2017. № 1172. P. 99-106. DOI: 10.17660/ActaHortic.2017.1172.18.

8. Сорокопудов В.Н., Князева И.В. Сохранение оздоровленных растений смородины черной для создания генетических банков // Субтропическое и декоративное садоводство. 2018. № 65. С. 87-92.

9. Лебедев А.А., Сковородников Д.Н. Оптимизация условий клонального микроразмножения Ribes nigrum L. (Grossulariaceae) // Бюллетень Брянского отделения РБО. 2016. № 1(7). C. 61-64.

10. Ковалева И.С., Мацнева А.Е., Ханбабаева O.E. [и др.]. Введение в культуру in vitro и клональное микроразмножение перспективного сеянца смородины черной (Ribes nigrum L.) // Вестник КрасГАУ. 2019. № 12. C. 43-48. DOI: 10.36718/1819-4036-2019-1243-48.

11. Князева И.В. Жизнеспособность микрорастений ягодных культур при длительном депонировании // Плодоводство и ягодоводство России. 2019. Т. 58. С. 240-245.

12. Skovorodnikov D.N., Kazakov I.V., Evdokimenko S.N., Sazonov F.F. Application of diphenylureaderivates in clonal micropropagation of primocane fruiting raspberry and black currants // Acta Hort. ISHS. 2012. № 946. P. 135-138.

13. Ишмуратова М.М., Головина Л.А. Размножение сортов смородины черной (Ribes nigrum L.) Башкирской селекции в культуре in vitro // Вестник Удмуртского университета 2017. Т. 27, вып. 4. С. 455-461.

14. Гусева К.Ю. Использование клонального микроразмножения для получения посадочного материала смородины черной Ribes nigrum L. // Инновационные направления развития сибирского садоводств: наследие академиков М.А. Лисавенко, И.П. Калининой: сб. ст. / Федеральный Алтайский научный центр агробиотехнологий. Барнаул, 2018. С. 81-85.

15. Sorokopudov V., Sorokopudova O., Knyazeva I., Burmenko J. Biotechnological methods of maintaining collections of the genus Ribes L. // Proceedings of the VIII International Scientific and Practical Conference «Biotechnolo- 
gy as an Instrumet for Plant Biodiversity Conservation (physiological, biochemical, embryological, genetic and legal aspects)». 2018. P. 197.

16. Brennan R.M., Jorgensen L., Hackett C., Woodhead M., Gordon S. and Russell J. The development of a genetic linkage map of blackcurrant (Ribes nigrum L.) and the identification of regions associated with key fruit quality and agronomic traits. // Euphytica 161, 2008. P. 19-34. DOI: 10.1007/s10681-0079412-8.

17. Brennan R.M., and Graham J. Improving fruit quality in Rubus and Ribes through breeding. // Funct. Plant Sci. Biotechnol. 3, 2009. P. 2229.

18. Hummer K.E. and Dale A. Horticulture of Ribes. // For. Pathol. 40, 2010. P. 251-263. DOI: 10.1111/j.1439-0329.2010.00657.

19. Межнина О.А., Урбанович О.Ю. Генетическое разнообразие сортов смородины черной (Ribes nigrum) в Белоруси // Весці Нацыянальнай акадэміі навук Беларусі. Серыя біялагічных навук. 2017. № 1. С. 62-69

20. Сорокопудов В.Н. Мелькумова Е.А. Биологические особенности смородины и крыжовника при интродукции: монография / Сиб. отд-ние. Новосибирск, 2003. 296 с.

21. Алексеенко Л.В., Высоцкий В.А. Методика регенерации плодовых и ягодных растений в культуре эксплантов различного происхождения. 2008. 25 с.

\section{Literatura}

1. Hai Ren, Haining Qin, Zhiyun Ouyang, Xiangying Wen, Lina Zhao Progress of implementation on the Global Strategy for Plant Conservation in (2011-2020) China // Biological Conservation. 2019. V. 230. P. 169-178. DOI: 10.1016/.biocon.2018.12.030.

2. Höfer M., Flachowsky H., Hanke M-V. German Fruit Genebank - looking back 10 years after launching a national network for sustainable preservation of fruit genetic resources // Journal für Kulturpflanzen. 2019. V. 71 (2/3). P. 41-51. DOI: 10.5073/JfK.2019.02-03.01.

3. Reed B.M. Cryopreservation of Temperate Berry Crops // Plant Cryopreservation: A Prac- tical Guide. New York: Springer Science Business Media LLC. 2008. P. 333-364.

4. Engelmann F., Gonzalez Arnao M.T., Wu Y., Escobar R.H. Development of Encapsulation Dehydration // Plant Cryopreservation: A Practical Guide. New York: Springer Science Business Media LLC. 2008. P. 59-76.

5. Koval'chuk I.Ju., Turdiev T.T. Optimizacija metodov kriokonservacii germoplazmy chernoj smorodiny (Ribes nigrum L.) // Biotehnologija. Teorija i praktika. 2010. № 2. S. 54-61.

6. Manole C.G., Balan V., Mencinicopschi I.C., Golea D., Rodino S., Butu A. The influence of growth regulators concentrations on in vitro micropropagation of Ribes rubrum Species // Scientific Bulletin, Series F, Biotechnologies. Vol. XVI. 2012. P. 26-29.

7. Volk G.M., Bramel P.A. Strategy to conserve worldwide apple genetic resources: survey results. // Acta Hortic. 2017. № 1172. P. 99-106. DOI: 10.17660/ActaHortic.2017.1172.18.

8. Sorokopudov V.N., Knjazeva I.V. Sohranenie ozdorovlennyh rastenij smorodiny chernoj dlja sozdanija geneticheskih bankov // Subtropicheskoe i dekorativnoe sadovodstvo. 2018. № 65. S. 87-92.

9. Lebedev A.A., Skovorodnikov D.N. Optimizacija uslovij klonal'nogo mikrorazmnozhenija Ribes nigrum L. (Grossulariaceae) // Bjulleten' Brjanskogo otdelenija RBO. 2016. № 1(7). S. 61-64.

10. Kovaleva I.S., Macneva A.E., Hanbabaeva O.E. [i dr.]. Vvedenie $v$ kul'turu in vitro $\mathrm{i}$ klonal'noe mikrorazmnozhenie perspektivnogo sejanca smorodiny chernoj (Ribes nigrum L.) // Vestnik Kras GAU. 2019. № 12. S. 43-48. DOI: 10.36718/1819-4036-2019-12-43-48.

11. Knjazeva I.V. Zhiznesposobnost' mikrorastenij jagodnyh kul'tur pri dlitel'nom deponirovanii // Plodovodstvo i jagodovodstvo Rossii. 2019. T. 58. S. 240-245.

12. Skovorodnikov D.N., Kazakov I.V., Evdokimenko S.N., Sazonov F.F. Application of diphenylureaderivates in clonal micropropagation of primocane fruiting raspberry and black currants // Acta Hort. ISHS. 2012. № 946. P. 135-138.

13. Ishmuratova M.M., Golovina L.A. Razmnozhenie sortov smorodiny chernoj (Ribes nigrum L.) Bashhkirskoj selekcii v kul'ture in 
vitro // Vestnik Udmurtskogo universiteta 2017. T. 27, vyp. 4. S. 455-461.

14. Guseva K.Ju. Ispol'zovanie klonal'nogo mikrorazmnozhenija dlja poluchenija posadochnogo materiala smorodiny chernoj Ribes nigrum L. // Innovacionnye napravlenija razvitija sibirskogo sadovodstv: nasledie akademikov M.A. Lisavenko, I.P. Kalininoj: sb. st. / Federal'nyj Altajskij nauchnyj centr agrobiotehnologij. Barnaul, 2018. S. 81-85.

15. Sorokopudov V., Sorokopudova O., Knyazeva I., Burmenko J. Biotechnological methods of maintaining collections of the genus Ribes L. / Proceedings of the VIII International Scientific and Practical Conference «Biotechnology as an Instrumet for Plant Biodiversity Conservation (physiological, biochemical, embryological, genetic and legal aspects)». 2018. P. 197.

16. Brennan R.M., Jorgensen L., Hackett C., Woodhead M., Gordon S. and Russell J. The development of a genetic linkage map of blackcurrant (Ribes nigrum L.) and the identification of regions associated with key fruit qual- ity and agronomic traits. // Euphytica 161, 2008. P. 19-34. DOI: 10.1007/s10681-0079412-8.

17. Brennan R.M., and Graham J. Improving fruit quality in Rubus and Ribes through breeding. // Funct. Plant Sci. Biotechnol. 3, 2009. P. 2229.

18. Hummer K.E. and Dale A. Horticulture of Ribes. // For. Pathol. 40, 2010. P. 251-263. DOI: 10.1111/j.1439-0329.2010.00657.

19. Mezhnina O.A., Urbanovich O.Ju. Geneticheskoe raznoobrazie sortov smorodiny chernoj (Ribes nigrum) v Belorusi // Vesci Nacyjanal'naj akadjemii navuk Belarusi. Seryja bijalagichnyh navuk. 2017. № 1. C. 62-69

20. Sorokopudov V.N. Mel'kumova E.A. Biologicheskie osobennosti smorodiny i kryzhovnika pri introdukcii: monografija / Sib. otd-nie. Novosibirsk, 2003. 296 s.

21. Alekseenko L.V., Vysockij V.A. Metodika regeneracii plodovyh i jagodnyh rastenij $\mathrm{V}$ kul'ture jeksplantov razlichnogo proishozhdenija. 2008. $25 \mathrm{~s}$. 